\title{
PEMETAAN PROFIL BUDAYA SOSIAL DAN KEARIFAN LOKAL DI DESA CINTARATU KABUPATEN PANGANDARAN
}

\author{
Rega Permana, Lantun Paradhita Dewanti dan Izza Mahdiana Apriliani \\ Fakultas Perikanan dan Ilmu Kelautan, Universitas Padjadjaran, Sumedang - Jawa Barat \\ E-mail: rega.permana@unpad.ac.id
}

\begin{abstract}
ABSTRAK. Desa Cintaratu terletak di Kabupaten Pangandaran merupakan wilayah pengembangan Program Studi Diluar Kampus Utama (PSDKU) Universitas Padjadjaran. Kehadiran PSDKU Unpad memberikan peluang pengembangan wilayah di Desa Cintaratu melalui pertumbuhan pendidikan dan ekonomi. Disisi lain hal ini dapat mengancam keberadaan budaya lokal yang merupakan warisan tradisi Desa seiring dengan datangnya pendatang dari luar. Untuk mengantisipasi hal tersebut, dilakukan pendataan profil budaya sosial dan kearifan lokal di Desa Cintaratu sebagai langkah awal dalam upaya preservasi budaya lokal. Tujuan dilakukannya penelitian ini adalah menelusuri profil kesenian tradisional dan budaya yang berbasis kearifan lokal di Desa Cintaratu. Penelitian ini dilakukan menggunakan metode survey dengan teknik pengambilan data secara observasi langsung di lapangan melalui wawancara kepada responden. Hasil yang didapatkan kemudian dianalisis secara deskriptif. Budaya sosial desa yang berhasil diidentifikasi antara lain adalah Ronggeng gunung, Ngupati, Kekeba, Gusaran, Ngabuku taun dan lain sebagainya. Beberapa budaya masih aktif dipraktikan oleh warga namun beberapa sudah tidak diselenggarakan. Hal ini disebabkan oleh berbagai faktor yang menjadi penghambat dalam proses pelestaraian budaya wilayah Desa Cintaratu. Secara keseluruhan, budaya dan kearifan lokal di wilayah Desa Cintaratu berhasil ditelusuri dan profil yang telah didapatkan dapat digunakan sebagai basis data untuk keperluan pengembangan wilayah desa terutama untuk antisipasi terhadap terjadinya disrupsi budaya.
\end{abstract}

Kata kunci: budaya; cintaratu; kearifan lokal; sosial

ABSTRACT. Located in Pangandaran Regency, Cintaratu village is home for the newly developed Program Studi Diluar Kampus Utama (PSDKU) Universitas Padjadjaran. The establishment of PSDKU Unpad is a spark of hope for the village development in terms of education and economic growth. On the other hand, this can jeopardize the existance of local culture which in forms of traditional herritage as the outsider came to the village. To anticipate that, there is an urgent need to perform the social culture and local wisdom profiling to maintain the local culture preservation. The aim of this research is to trace the local culture and wisdom in Cintaratu Village. This research was conducted using survey method with direct observation as the technique for data collection through deep interview with respondens. The acquired results will be analyzed descriptively following to the qualitative measurement. The results showed that several culture succesfully identifed were Ronggeng gunung, Ngupati, Kekeba, Gusaran, Ngabuku taun etc. Some were still practiced by the locals while some were not. This could be triggered by various factor resisting the preservation of local culture in the village. Overall, culture and local wisdom in Cintaratu Village have been traced and this profile can be utilized as the data base for village development particularly for anticipating the cultural disruption that might happen in the future.

Key words: cintaratu; culture; local wisdom; social

\section{PENDAHULUAN}

Kabupaten Pangandaran yang diproyeksikan akan menjadi wilayah sentra pariwisata di Provinsi Jawa Barat memiliki banyak pekerjaan rumah untuk dibenahi baik itu dari segi sistem pengelolaan maupun infrastrukturnya. Potensi alam dan budaya serta kesenian tradisional di masing-masing kecamatan di Kabupaten Pangandaran perlu dioptimalkan dalam upaya mendukung tumbuhnya iklim pariwisata yang berkelanjutan (Komariah et. al., 2017). Desa Cintaratu yang terletak di Kecamatan Parigi Kabupaten Pangandaran, merupakan salah satu kawasan potensial untuk dikembangkan sebagai daerah wisata khususnya wisata budaya dan seni. Mengingat lokasi Desa Cintaratu yang dilalui oleh beberapa titik wisata populer di Kabupaten Pangandaran, seperti Pantai Batu Hiu dan Batu Karas. Kesenian dan budaya kearifan lokal apabila tetap dijaga dengan baik dapat dijadikan sebagai modal pariwisata yang potensial disamping sebagai upaya pelestarian budaya lokal.
Hal ini dapat kita lihat sebagai contoh pada kawasan budaya di Pulau Bali (Nalayani, 2016) atau di Daerah Istimewa Yogyakarta (Susilo dan Soeroso, 2014). Disamping menawarkan pesona alam yang indah dan terjaga, unsur budaya yang kental menjadi daya tarik wisatawan baik itu nasional maupun mancanegara. Beberapa faktor yang mendukung suksesnya pengembangan daerah wisata budaya diantaranya adalah partisipasi komunitas lokal serta dukungan pemerintah (Xie, 2001; Abuamoud et al. 2014). Namun menurut Murphy dan Boyle (2006) hal yang paling mempengaruhi keberhasilan pengembangan wisata budaya adalah karakteristik kontekstual budaya di setiap daerah, dimana hal itu akan memberikan kesan unik dan eksklusif. Maka dari itu, strategi awal dalam pengembangannya adalah mengenali potensi wilayah melalui inventarisasi dan profiling budaya. Kabupaten Pangandaran dengan kebudayaan khas pesisir dan kesundaannya dapat dijadikan daya tarik apabila dikemas secara menarik dengan tetap memperhatikan kearifan lokal yang ada. 
Selain itu, pada tahun 2016 wilayah kabupaten Pangandaran menjadi wilayah pembangunan Program Studi di Luar Kampus Utama Universitas Padjadjaran (PSDKU Unpad) (Sukoco dan Fordian, 2019). Pembangunan kampus ini akan turut serta dalam percepatan pembangunan di wilayah Desa Cintaratu terutamadibidang ekonomidan pendidikan. Hadirnya PSDKU Unpad akan menumbuhkan flux ekonomi yang positif di sekitar desa, namun disisi lain dapat menimbulkan terjadinya disrupsi budaya dan kearifan lokal karena berdatangannya masyarakat atau mahasiswa dari luar wilayah Desa Cintaratu.

Sejauh ini, belum ada data terstruktur mengenai kesenian dan budaya kearifan lokal yang berasal dari Desa Cintaratu yang terdokumentasi dengan baik. Kegiatan penelitian dan pengabdian kepada masyarakat ini bertujuan untuk menelusuri profil kesenian tradisional dan budaya yang berbasis kearifan lokal di Desa Cintaratu. Data profil tersebut penting untuk dipetakan selain sebagai dasar dalam upaya konservasi budaya, dapat pula dijadikan basis dalam pengembangan wilayah - wilayah potensial yang berasosiasi dengan budaya atau kesenian tertentu hingga memudahkan penyusunan prioritas pengembangan desa.

\section{METODE}

Kegiatan ini dilaksanakan dengan objek observasi adalah budaya lokal yang ada di Desa Cintaratu. Target kegiatan pengabdian kepada masyarakat ini adalah tersusunnya profil sosial budaya yang melekat di Desa Cintaratu. Metode yang digunakan dalam pelaksanaan kegiatan adalah metode survey. Metode survey adalah metode riset yang bertujuan untuk mendapatkan data yang valid dengan memberi batas yang jelas atas data kepada suatu objek tertentu (Suyanto, 2015). Batas yang dimaksud dalam kegiatan ini adalah budaya lokal yang berupa nilai kearifan lokal dan modal sosial. Teknik pengambilan data dengan cara observasi langsung lapangan melalui wawancara dan focus group discussion (FGD) kepada responden yang merupakan warga penggiat budaya di wilayah Desa Cintaratu. Menurut Dunn dalam Riant (2004) pengambilan data dilengkapi dengam teknik evaluasi berupa Participatory Rural Appraisal (PRA), yaitu teknik yang melibatkan masyarakat untuk turut serta dalam membuat tindakan nyata yang berpengaruh terhadap kehidupannya.

Prinsip-prinsip penerapan PRA (Adimihardja \& Hikmat, 2003) adalah sebagai berikut:

1. Masyarakat dipandang sebagai subjek bukan objek;

2. Peneliti memposisikan dirinya sebagai insider bukan outsider; dan
3. Pemberdayaan dan partisipatif masyarakat dalam menentukan indikator sosial (indikator evaluasi partisipatif).

Kegiatan ini merupakan kegiatan pengumpulan basis data nilai kebudayaan yang melekat di Desa Cintaratu. Hasil dari kegiatan ini memetakan kebiasaan, nilai - nilai yang ada di masyarakat dan mengidentifikasi nilai kearifan lokal dan modal sosial (trust, norm, network) yang kemudian disusun menjadi inventaris desa sehingga dapat digunakan untuk kepentingan pengembangan desa. Identifikasi tantangan dan peluang juga dilakukan untuk memetakan strategi pengembangan melalui analisis SWOT (Strength, Weekness, Opportunity, Threat).

\section{HASIL DAN PEMBAHASAN}

Desa Cintaratu memiliki potensi sumber daya manusia, sumber daya alam, dan sumber budaya yang cukup melimpah. Adanya sumber daya manusia yang ahli di bidang seni maupun dibidang usaha di berbagai bidang, memiliki sumber daya alam yang melimpah dari hasil perkebunan, peternakan dan perikanan, menambah potensi ekonomi kreatif untuk kesejahteraan masyarakat Desa Cintaratu (Hidayat, 2011; Hertanti, 2019). Kebudayaan yang berada di Desa Cintaratu Kecamatan Parigi Kabupaten Pangandaran Provinsi Jawa Barat ini merupakan salah satu modal utama pembangunan yang melandasi program yang akan dilaksanakan oleh desa. Salah satu warisan budaya dari para leluhur dimasa lalu patut untuk dijaga kelestariannya, hal tersebut merupakan rangka dasar bagi pengembangan obyek pariwisata budaya.

Berdasarkan hasil observasi yang telah dilakukan selama kegiatan pengabdian kepada masyarakat ini, dapat diidentifikasi beberapa peluang dan tantangan dalam hal konservasi dan pengembangan budaya sosial di Desa Cintaratu. Hal ini dapat dilihat dari hasil analisis SWOT (Gambar 1) yang memetakan kekuatan, kelemahan, peluang dan ancaman dalam upaya pengembangan budaya di Desa Cintratu terutama dikaitkan dengan hadirnya PSDKU Unpad sebagai motor penggerak ekonomi dan pendidikan desa. Potensi sumber daya alam, warisan budaya serta letaknya yang berada di jalur wisata Kabupaten Pangandaran, merupakan kekuatan yang unggul dimiliki oleh Desa Cintaratu sementara kurang tersedianya sumberdaya manusia yang berpendidikan dan partisipasi aktif pemerintah menjadi kelemahan utama dalam pengembangan budaya di Desa Cintaratu. Namun hal ini dapat diatasi dengan hadirnya PSDKU Unpad yang dapat menjadi peluang sekaligus ancaman khususnya dalam preservasi warisan budaya. Kehadiran 
PSDKU Unpad akan memberikan pengaruh pada kualitas pendidikan warga sekitar dengan tersedianya akses warga terhadap pendidikan tinggi. Selain itu kehadiran PSDKU Unpad akan menstimulasi tumbuhnya perekonomian wilayah sekitar desa. Namun hal ini juga dapat menjadi ancaman dimana PSDKU Unpad dapat membawa arus budaya luar yang dapat mengancam keberadaan budaya lokal Desa Cintaratu, atau terjadinya disrupsi budaya. Pengelolaan dan kerjasama antar berbagai pihak baik itu pemerintah, akademisi, industri dan masyarakat setempat menjadi kunci dalam pengembangan budaya di wilayah Desa Cintaratu.

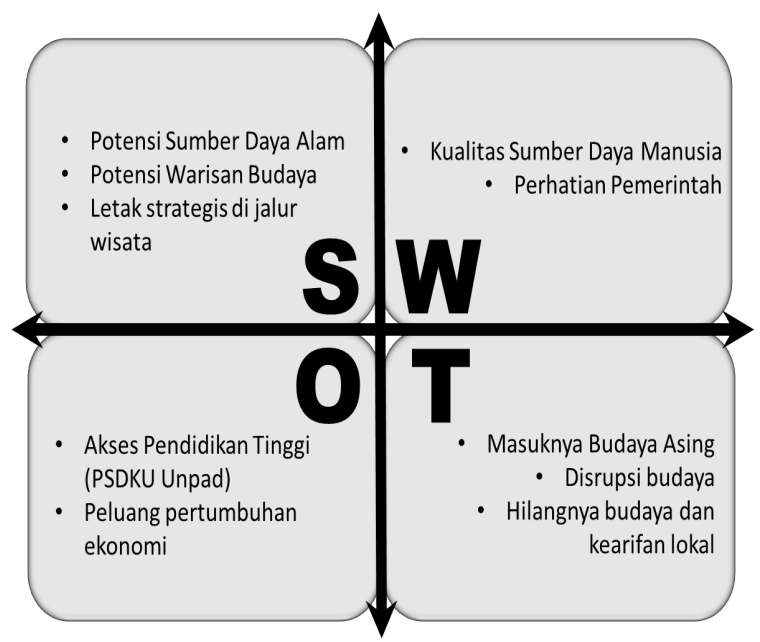

Gambar 1. Analisis SWOT Pengembangan Budaya di Desa Cintaratu

Desa Cintaratu memiliki potensi daerah wisata alam Jojogan yang berada di Dusun Gunung Tiga. Wisata alam jojogan menyajikan pemandangan alam yang indah nan asri dan juga terdapat wahana air. Wisata jojoga kini di kelola oleh karang taruna daerah setempat. Wisata jojogan kerap dikunjungi oleh wisatawan domestik ataupun mancanegara. Berdasarkan hasil pencarian informasi yang didapat bahwa wisata alam jojogan seiring berjalanya waktu terdapat penurunan jumlah wisatawan. Desa Cintaratu juga memiliki warisan kebudayaan kesenian ronggeng gunung yang sampai saat ini masih aktif. Terdapat beberapa kelompok maupun perorangan yang memiliki keahlian di bidang kesenian dan kebudayaan mulai dari seni rupa dan seni musik. Dari segi fasilitas kesenian Desa Cintaratu terdapat Padepokan sanggar seni Dangiang Mustika Sari yang terdapat di Dusun Cintasari. Sanggar tersebut terbuka untuk umum siapapun yang ingin belajar dapat bergabung tanpa ada tarikan biaya. Desa Cintaratu memiliki tradisi daerah setempat diantaranya wawacan, ngupati, kekeba, gusaran dan lain-lain. Seiring berjalannya waktu beberapa tradisi tersebut mulai tidak aktif. Rincian kesenian dan tradisi masyarakat yang ada di Desa Cintaratu dapat dilihat di Tabel 1.
Tabel 1. Budaya dan Tradisi di Desa Cintaratu

\begin{tabular}{cc}
\hline Nama Budaya dan Tradisi & Keterangan \\
\hline Ronggeng Gunung & Aktif \\
Ronggeng Amen & Aktif \\
Wawacan & Tidak aktif \\
Ngabuku Taun & Aktif \\
Opat Bulanan (Ngupati) & Aktif \\
Tujuh Bulanan (Kekeba) & Aktif \\
Mapag Panen & Tidak aktif \\
Anter-anter & Tidak aktif \\
Babarit & Aktif \\
Gusaran & Aktif \\
Reog (dog dog) & Tidak aktif \\
\hline
\end{tabular}

\section{Ronggeng Gunung}

Ronggeng gunung merupakan kesenian khas Pangandaran. Ronggeng gunung lahir pada tahun 1725 sejak zaman kerajaan. Dahulu keseniaan ini pernah diperebutkan oleh Ciamis yang menginginkan kesenian ronggeng gunung dijadikan kesenian khas Ciamis, namun berdasarkan beberapa catatan sejarah bahwa pertama kali pagelaran kesenian ronggeng gunung berada di tatar pakidulan Pangandaran. Oleh karena itu, kesenian ini tidak diberikan oleh pihak Pangandaran dan akhirnya ronggeng gunung tetap menjadi kesenian khas Pangandaran.

Pagelaran ronggeng gunung biasanya ditampilkan di hajatan atau khitanan, di acara hari kemerdekaan ataupun undangan dari acara yang digelar di kabupaten. Ronggeng gunung di mainkan oleh anak-anak dan dewasa dengan jumlah pemain 4 orang (gendang, bonang, goong dan ngawih atau penyanyi). Para pemain laki-laki biasanya menggunakan pakaian pangsi hitam dan perempuan mengenakan kebaya. Di Desa Cintaratu hanya ada 1 kelompok kesenian ronggeng gunung yang berada di Dusun Gunungtiga. Lagu pokok yang biasa digunakan untuk mengiringi diantaranya menangis, raja pulang, golewang, sasagaran, dan liring.

\section{Ronggeng Amen}

Ronggeg Amen merupakan pengembangan dari Ronggeng Gunung. Perbedaan Rongeng Gunung dan Ronggeng Amen terletak dari dari jumlah alat musik yang digunakan. Ronggeng amen alatnya lebih bervariasi. Para pemain ronggeng amen yang ada di sanggar merupakan kolaborasi dengan warga dari daerah lain seperti Cijulang, Parigi dan lain-lain. Pagelaran rutinjikaadaundangandihajatan, pasanggiri, dan lain-lain. Faktor awal kurang berkembangnya kesenian ronggeng karena kurangnya perhatian dari pemerintah setempat yang kurang menyadari adanya aset kebudayaan yang ada. Pagelaran seni ini hanya diadakan ketika adanya pengunjung yang memang ingin mengenal lebih tentang kesenian dan pada acara tertentu atau hari-hari besar. 


\section{3. $\operatorname{Reog}(\operatorname{dog} \operatorname{dog})$}

Dogdog merupakan kesenian sunda yang merupakan warisan karuhun warga sunda, dogdog kreasi merupakan kesenian dogdog yang sudah dikreasikan lagi salah satunya oleh Komunitas Iket Sunda Pangandaran (KIS Pangandaran). Dogdog sering di gelar di Pangandaran untuk memeriahkan upacara adat seperti seren taun, sedekah bumi, hajat laut, sambutan, ruwatan, perkawinan dan lain-lain.

\section{Ngupati}

Pada saat empat bulan ini, awal pertama bayi di dalam kandungan diberikan nyawa atau roh. Sehingga, acara empat bulanan dianggap penting dan harus dilakukan. Kegiatan yang dilakukan pada saat acara empat bulanan diantaranya ibu yang sedang hamil dimandikan dengan air tujuh sumur, bunga tujuh macam dengan menggunakan kain samping sebanyak tujuh kain yang dilingkarkan ke badan lalu ada kendi yang berisi belut nantinya akan dimasukan dan dijatuhkan. Masyarakat mempercayai kendi yang berisi belut lalu dijatuhkan bermakna bahwa nanti pada saat proses lahiran dapat berjalan dengan lancar. Adapun kelapa gading yang di lukis dengan gambar wayang lalu nantinya kelapa akan dibelah dalam satu pukulan. Jika belahan simetris bermakna bayi yang akan lahir laki-laki, jika belahan tidak simetris makan bayi yang akan lahir berjenis kelamin perempuan. Lalu ibu akan melakukan jual rujak namun yang membeli harus menggunakan uang benggol (uang berbahan dasar dari genteng yang dibentuk lingkaran). Sampai saat ini masyarakat masih ada yang melakukan tradisi ini, tergantung kemampuan dari individu masing masing. Biasanya saat malam hari diadakan pengajian yang dipimpin oleh ustadz setempat. Namun pada saat proses acara di siang hari di pandu oleh dukun beranak (guguni).

\section{Kekeba}

Di Desa Cintaratu Kecamatan Parigi Kabupaten Pangandaran, ada beberapa orang yang masih tetap melaksanakan tradisi kekeba ini. Ketika seorang ibu yang sedang mengandung memasuki usia kehamilan 7 bulan, maka akan mengadakan acara kekeba. Acara ini di isi dengan pengajian, membuat tumpeng, dan masakan-masakan biasa lainnya sesuai dengan kemampuan keluarga. Ada ritual khusus untuk ibu yang sedang mengandung yaitu si ibu di pakaikan 7 samping dan di mandikan sedangkan untuk sang suami di haruskan memanjat pohon kelapa. Kelapa yang didapatkan lalu di gambar di kedua sisi yang berbeda dengan gambar wajah laki-laki dan wajah perempuan sebagai bentuk penerimaan bayi lakilaki atau perempuan yang akan di lahirkan nantinya lalu kelapa dimasukan ke dalam kain samping dan di biarkan terjatuh sampai pecah, jika kelapa tidak pecah, kelapa di pecahkan menggunakan golok.

\section{Gusaran}

Acaragusaranmerupakantradisipenggosokangigi menggunakan koin uang recehan biasanya dilakukakan pada anak perempuan atau pun laki-laki. Pada anak laki- laki biasanya bersamaan dengan sunatan. Seorang anak perempuan dimandikan lalu nanti setelah mandi di rias dan setelah itu giginya di gosok menggunakan uang koin benggol. Tujuan gusaran untuk mensucikan anak tersebut. Saat proses dimandikan tidak ada air yang di khususkan. Saat ini masih ada masyarakat Desa Cintaratu yang melakukan gusaran sesuai dengan kemampuan individu masyarakat. Tradisi gusaran dilakukan pada anak.

\section{Ngabuku Taun}

Tradisi ini biasa dilaksanakan pada 1 Muharram, dengan maksud untuk memeriahkan pergantian tahun baru islam dan sering di sebut juga Ruat Bumi. Masyarakat makan bersama di lingkungan sekitar. Tradisi ini bisa dijadikan sebagai ajang silaturahmi antar warga, untuk meminimalisisir anggapan yang bertentangan dengan agama maka dalam ngabuku taun ini diselipkan ceramah atau pengajian. Pada saat ini juga ada proses penyampaian Laporan Pertanggung Jawaban (LPJ) hasil kerja tahun sebelumnya dari ketua RT kepada masyarakat. Dalam tradisi ini masyarakat sekitar ikut berpartisipasi. Terdapat makanan yang dikhususkan pada kegiatan ini yaitu berupa makanan hasil bumi. Tidak ada pakaian yang dikhususkan pada saat kegiatan ini. Tradisi yang masih kuat ada di Desa Cikalong. Dusun yang masih kuat melaksanakan tradisi ada di Dusun Panglanjan dan di beberapa dusun masih melaksanakan namun namanya sedikit di ubah contonhnya menjadi Muharaman namun acaranya tetap sama.

\section{Mapag Panen}

Tradisi ini umum dilakukan di sawah oleh para petani. Petani ketika hendak panen biasanya melakukan nyanggar dengan meletakkan sesajen di tengah sawah saat siang atau sore hari dan besoknya diambil kembali. Selain sesajen juga melakukan permintaan atau doa-doa tertentu. Tradisi ini dilakukan secara individu. Tidak ada hari yang dikhususkan untuk pelaksanaan ini. Ketika mau panen biasanya melakukan nga etem atau memotong beberapa helai padi lalu di bawa ke rumah. Tujuannya supaya padi terisi dan panen melimpah banyak. Mapag panen sekarang sudah jarang terlihat lagi, dikarenakan mungkin pemilik atau orang yang melakukannya merasa hal tersebut bertentangan dengan agama. Mungkin masih ada tetapi pelaku melakukannya secara sembunyi-sembunyi karena sudah tidak ada lagi yang melakukan hal tersebut.

\section{Wawacan}

Wawacan atau eok yang dilakukan pada saat syukuran bayi baru lahir atau akikahan, namun 
budaya ini sudah jarang karena pelaku tokohnya sudah banyak yang meninggal dan tidak ada generasi penerusnya. Wawacan merupakan dongengan untuk bayi dalam bentuk tembang atau nyanyian dalam bentuk kawih yang di dalamnya terdapat pupuh buhun yang dimuat dalam tulisan arab gundul. Acara ini juga berisi dengan pembacaan kitab berjanjen dan berlangsung dari malam sampai subuh menurut kepercayaan bapak-bapak, wawacan tersebut di maksudkan menemani si ibu bayi yang menyusui anaknya supaya tidak tertidur dan membantu menidurkan bayinya. Dalam dongeng tersebut mengandung unsur nasihat. Tradisi ini masih dilakukan di Dusun Panglanjan Desa Cintaratu.

\section{Babarit}

Dilakukan pada setiap malam jumat kliwon ketika sesudah ada kejadian tertentu, misalnya gempa, tujuannya untuk buang sial. Kegiatan saat tradisi ini biasanya ada proses berdo'a, makan bersama di lingkungan sekitar. Sekarang babarit sudah langka dan hampir tidak dilakukan dikarenakan masyarakat kurang aktif lagi dan tidak ada penggeraknya. Biasanya di pimpin oleh sesepuh lingkungan beserta para RT dengan melibatkan semua masyarakat.

\section{Anter-anter}

Anter-anter adalah tradisi tukar-menukar makanan ke sodara yang disesuaikan dengan kondisi individu masing-masing. Seminggu sebelum hari raya idul fitri adalah waktu pelaksanaan tradisi Anteranter dilakukan. Biasanya anak kecil akan diberi uang jika mengantarkan makanan sebagai upah. Karena dulu Desa Cintaratu masih banyak yang memiliki balong atau kolam ikan, biasanya setiap lebaran akan mengadakan pesta membedahkan balong.

\section{SIMPULAN}

Berdasarkan hasil kegiatan pengabdian kepada masyarakat ini dapat disimpulkan bahwa pendataan profil budaya di wilayah Desa Cintaratu telah berhasil dilakukan dan dapat memberi gambaran mengenai prioritas warisan budaya yang perlu dilestarikan untuk antisipasi disrupsi budaya. Profil budaya ini juga dapat digunakan sebagai basis data untuk dikembangkan lebih lanjut dalam pengembangan wilayah Desa Cintaratu. Rekomendasi yang dapat diberikan berupa kerjasama antar berbagai pihak baik itu pemerintah, akademisi, industri dan masyarakat setempat untuk inisiasi pengembangan budaya lokal di Desa Cintaratu.

\section{UCAPAN TERIMAKASIH}

Penelitian ini dapat dilaksanakan dengan baik menggunakan dana hibah pengabdian yang diberi-kan oleh direktorat riset, pengabdian kepada masyarakat dan inovasi(DRPMI) Universitas Padjadjaran(Unpad) melalui skema Kuliah Kerja Nyata Mahasiswa
(KKNM) Integratif Pengabdian Pada Masyarakat (PPM). Ucapan terima kasih juga diberikan kepada para mahasiswa peserta KKNM yang membantu pencarian data serta pada perangkat Desa Cintaratu yang menyediakan data yang dibutuhkan.

\section{DAFTAR PUSTAKA}

Abuamoud, I. N., Libbin, J., Green, J., \& ALRousan, R. (2014). Factors affecting the willingness of tourists to visit cultural heritage sites in Jordan. Journal of Heritage Tourism, 9(2), 148165.

Adimihardja dan Hikmat. (2003). Participatory Appraisal dalam Pelaksanaan Pengabdian Kepada Masyarakat. HUP Bandung.

Dunt,NdanRiant.(2004). Kebijakan Publik, Formulasi, Implementasi, dan Evaluasi. Jakarta:Gramedia

Hertanti, S. (2019). PelaksanaanProgramKarang Taruna dalam Upaya Meningkatkan Pembangunan Di Desa Cintaratu Kecamatan Parigi Kabupaten Pangandaran. MODERAT: Jurnal Ilmiah Ilmu Pemerintahan, 4(4), 69-80.

Hidayat, M. (2011). Strategi Perencanaan dan Pengembangan Objek Wisata (Studi Kasus Pantai Pangandaran Kabupaten Ciamis Jawa Barat). THE Journal: Tourism and Hospitality Essentials Journal, 1(1), 33-44

Komariah, N., Yusup, P. M., Saepudin, E., dan Rodiah, S. (2017). Pendidikan Literasi Lingkungan Sebagai Penunjang Desa Wisata Agro Kecamatan Padaherang Kabupaten Pangandaran. Dharmakarya, 6(2), 111-115

Murphy, C., \& Boyle, E. (2006). Testing a conceptual model of cultural tourismdevelopmentinthepostindustrial city: A case study of Glasgow. Tourism and Hospitality Research, 6(2), 111-128.

Nalayani, N. N. A. H. (2016). Evaluasi dan Strategi Pengembangan Desa Wisata di Kabupaten Badung, Bali. Jurnal Master Pariwisata (JUMPA).

Sukoco, I., dan Fordian, D. (2019). Sosialisasi Keberadaan Psdku Unpad Pangandaran Kepada Siswa Slta Se-Kapupaten Pangandaran. Dharmakarya, 8(1), 70-73.

Susilo, Y. S., dan Soeroso, A. (2014). Strategi pelestarian kebudayaan lokal dalam menghadapi globalisasi pariwisata: Kasus Kota Yogyakarta. Jurnal Penelitian BAPPEDA Kota Yogyakarta, 4, 3-11.

Suyanto, B. (2015). Metode Penelitian Sosial: Berbagai Alternatif Pendekatan. Prenada Media.

Xie, P. F. (2001). Authenticating cultural tourism: Folk villages in Hainan, China. $\mathrm{PhD}$ Dissertation. UWSpace. 